\title{
Improving bioaerosol exposure assessments - comparative modelling of emissions from different compost ages and activities
}

\author{
Atmospheric Environment, Volume 41, Issue 21, July 2007, Pages 4504-4519
}

\author{
M.P.M. Taha ${ }^{1}$, G.H. Drew ${ }^{1}$, A. Tamer ${ }^{1}$, G. Hewings ${ }^{2}$, G. Jordinson ${ }^{3}$, P.J. Longhurst ${ }^{1}$ and \\ S.J.T Pollard ${ }^{1 *}$ \\ ${ }^{1}$ Integrated Waste Management Centre, Sustainable Systems Department, School of Applied \\ Sciences, Cranfield University, Cranfield, Bedfordshire, MK43 OAL, UK \\ ${ }^{2}$ Cardiff School of Engineering, The Research Office, Queen's Building, P.O. Box 925, \\ Cardiff, CF24 OYF, Wales, UK \\ ${ }^{3}$ Environment Agency, Evenlode House, Howbery Park, Wallingford, Oxfordshire, OX10 \\ $8 B D, U K$
}

\begin{abstract}
We present source term data from both passive and active sources, and compare emissions from compost aged at 1, 2, 4, 6, 8, 12 and 16 weeks. The results reveal that the age of compost has little effect on the concentrations emitted. The bioaerosol emissions from passive sources were in the range of $10^{3}-10^{4} \mathrm{cfu} / \mathrm{m}^{3}$, with releases from active sources usually 1-log higher. We propose further improvements to current risk assessment methodologies by examining the differences between two air dispersion models for the prediction of downwind bioaerosol concentrations of off-site points of exposure. Our results show that SCREEN3 provides a conservative estimate of the source depletion curves of bioaerosol emissions in comparison to ADMS 3.3. However, the results from both models


predict that bioaerosol concentrations may decrease to below background concentrations before $250 \mathrm{~m}$, the distance at which the Environment Agency may require a risk assessment to be completed.

Keywords: bioaerosols, compost, dispersion, modelling

\section{Introduction}

\section{$1.1 \quad$ Background}

The composting process is reliant on the presence of various micro-organisms, such as fungi and bacteria, which may become airborne and pose a risk to human health (Douwes et al., 2003). In partial response to perceived public health concerns, the Environment Agency of England and Wales require a risk assessment to be undertaken for composting facilities of a certain size that have a sensitive receptor within $250 \mathrm{~m}$ of their boundaries, which should examine, among other hazards, the dispersal of airborne micro-organisms or bioaerosols from the site (Wheeler et al., 2001; Environment Agency, 2002; Pollard et al., 2006). In the context of a risk assessment, sensitive receptors may include a residence, school or office building. The aim of the risk assessment is to provide a useful tool for risk management. However, the quality of the risk assessment is dependant on the availability and quality of the bioaerosol source term data (among other things) employed (Pollard et al., 2006). This data is frequently limited, in part because of the practical difficulties of microbiological analyses but also due to cost constraints.

There is a growing body of research that examines the concentrations of bioaerosols in and around composting facilities (e.g. Danneberg et al., 1997; Swan et al., 2002; SanchesMonedero and Stentiford, 2003). Many studies that attempt to predict the dispersal of bioaerosols from facilities use simple methods or dispersion models (e.g. Millner et al., 1980, Lighthart and Mohr, 1987; Swan et al., 2003; ADAS/SWICEB, 2005) and thus produce risk 
estimates that are overly conservative. Air dispersion models were developed to predict dispersion of pollutants, such as the nitrogen oxides, and have also successfully been used for assessing odour dispersion from industry (e.g. Environment Agency, 2002). However, the use of these models for bioaerosol dispersion has been limited, as dispersion models may not be able to take into account the mechanisms of release of bacteria and fungi.

According to McCartney (1994), environmental factors such as wind speed, turbulence, humidity and water availability will influence when spores are released. Although these parameters are taken into account by dispersion models when predicting downwind concentrations, there are very few 'at source' measurements of bioaerosol concentrations that link these parameters to the concentrations measured. Furthermore, certain characteristics of bioaerosols complicate the use of dispersion models and, in particular, their ability to form aggregates or clumps once released, and the loss of viability that may occur as they are emitted from the compost windrow (Wheeler et al., 2001).

Our own research (Taha et al., 2004; 2005; 2006a; 2006b) focuses on improving the quality of regulatory risk assessments for composting by providing:

i. accurate source term data at the point of release (Taha et al., 2006a); and

ii. developing new methods for improving sampling and enumeration of bioaerosols (Taha et al., 2006b).

Here, we propose further improvements by presenting the refinement of air dispersion modelling for the prediction of downwind bioaerosol concentrations of off-site points of exposure.

\subsection{Study Rationale}

In this paper, we present results from measuring the dispersal of bioaerosols from a green waste composting research facility in southern Wales. The advantage of sampling at a 
research facility was that the processes on site could be adjusted to aid the sampling activities, for example, timing of shredding and screening. The objectives of the study were (i) to characterise the source term bioaerosol emissions, taking into consideration storage properties, compost age and dispersal during agitation using a windrow turner, front-end loader, screener and shredder; and (ii) to compare the predicted downwind concentrations modelled by two separate dispersion models. We seek to improve bioaerosol exposure assessments by refining the methods currently used to estimate downwind dispersal of compost emissions.

In order to estimate static pile emission flux rate and bioaerosol active dispersal emission rate during agitation, the conservative SCREEN3 (USEPA, 1995a) model was used to initially estimate bioaerosol depletion curves. SCREEN3 is a screening-level model that adopts steady-state Gaussian plume algorithms and meteorological scenarios to estimate worst-case dispersal. This was followed by application of more advanced modelling using the ADMS 3.3 air dispersion model (Carruthers et al., 1994; CERC, 2003). ADMS is an advanced steady state, Gaussian-like dispersion model, capable of modelling continuous plumes, short duration releases and transport over complex terrain. The model simulates point, line, area and volume sources, and can estimate pollutant concentrations at a number of user defined receptors. The model has been shown to perform in a comparable manner to similar new generation models (Hanna et al., 2000). Using the model results, we infer the possible influences that bioaerosol properties such as inactivation and microbial agglomeration may have on the depletion curves (concentration with distance) and concentration with distance produced by the models.

\section{Material and Methods}


The study site is a research composting facility handling $c a .12000 \mathrm{~m}^{3}$ of shredded green waste per annum in windrows under a $1500 \mathrm{~m}^{2}$ building with open sides. Samples were taken from compost windrows (passive emissions) aged at 1, 2, 4, 6, 8, 12 and 16 weeks, and during agitation activities (active emissions) on site, such as turning, shredding and screening. For turning activities, measurement was conducted on 1, 4, 8 and 12 weeks. Sampling was undertaken between January and March 2005.

\section{$2.1 \quad$ Bioaerosol sampling}

Direct sampling of bioaerosols from static compost windrows was undertaken using a portable wind tunnel (Jiang et al., 2000; Taha et al., 2005; 2006a) positioned on the compost windrows to allow the direct measurement of the bioaerosol flux. Incoming air, filtered through activated carbon is blown into the inlet duct using a fan. Bioaerosols are mixed into the bulk of the carrier air and vented from the hood to the sampling device.

For safety and practical reasons, it was not possible to use the portable wind tunnel during compost processing activities. Instead, bioaerosols were sampled at the closest safe and practical distance $(5-10 \mathrm{~m})$ downwind of various process activities. These distances are much closer to operations than in many other studies (e.g. ADAS/SWICEB, 2005). The airborne micro-organisms were collected onto filter media using a medium flow pump followed by elution and plating. The flow rate was $c a .21 / \mathrm{min}$ and the filter media used was $0.8 \mathrm{~mm}$ polycarbonate. Mean wind speed (max and mean) and temperature $(\mathrm{K})$ during sampling were recorded using a thermal anemometer (Testo 425). Three successive samples were taken over a 45 min sampling interval during turning. Samples were taken during green waste screening, compost turning, and compost loading operations.

Control (i.e. on-site background) bioaerosol concentrations were measured at a height of $1.8 \mathrm{~m}$, at positions up- and downwind $(5-10 \mathrm{~m})$ of the compost windrows, using the method 
described above for active sampling. This method was also used to sample the air directly above the compost pile $(0.3 \mathrm{~m})$.

\subsection{Sample collection and preservation}

The methods used for sample collection and preservation are described in Taha et al. (2006a). In both the active and passive release modes above, bioaerosols were sampled using a medium flow, personal aerosol filter sampler (SKC Universal dust and vapour sampling pump). The pump was operated at $2.0 \pm 0.1 \mathrm{1} / \mathrm{min}$ and fitted with SKC dust sampling Institute of Occupational Medicine (IOM) heads (25mm) (Wheeler et al., 2001), loaded with mixed cellulose ester filters ( $25 \mathrm{~mm}$ x $0.8 \mu \mathrm{m}$ pore size). Microorganisms were quantified using the CAMNEA-method (Collection of Airborne Microorganisms on Nuclepore filters, Estimation and Analysis) (Palmgren et al., 1986). The cellulose ester filters were placed inside a $30 \mathrm{ml}$ vial (Nalgene) containing $10 \mathrm{ml} 0.05 \%$ v/v Tween- 80 mixed with $0.1 \%{ }^{\mathrm{w}}{ }_{\mathrm{w}} \mathrm{NaCl}$ to prevent cell osmosis and stored within a cold box at $<4^{\circ} \mathrm{C}$. On return to the laboratory, bioaerosols were re-suspended by agitating the filter, the filter casing and the amended Tween-80 solution together in the vial for $c a .2$ minutes. The solution was diluted in a common logarithm order and inoculated within 48 hours on agar plates to prevent sporulation of micro-organisms leading to erroneous results.

\subsection{Bioaerosol enumeration}

Aspergillus fumigatus and actinomycetes sampled during active processing operations and from static compost windrows were enumerated by visual inspection. Media preparation, inoculation, dilution and sterilisation were performed in accordance with BS 5763: Part

0:1996. For actinomycetes, two media were used and developed simultaneously:

(i) half strength nutrient agar (Oxoid); and 
(ii) soil compost agar (a supernatant of $10 \% \mathrm{w} / \mathrm{w}$ of loam-based compost John Innes No. 1 compost in agar).

Further details are reported in Taha et al. (2006b). After preparation, both media were autoclaved $\left(105^{\circ} \mathrm{C}, 15 \mathrm{~min}\right)$, left to cool to below $47^{\circ} \mathrm{C}$ and treated with $1 \% \mathrm{v} / \mathrm{v}$ antifungal cycloheximide, dissolved in less than $2 \mathrm{ml}$ of ethanol. For A. fumigatus, malt extract agar (Merck) was mixed with $0.01 \%$ w/w antibacterial chloramphenicol (Sigma, UK). Nutrient agar plates and soil compost agar plates were incubated at $44^{\circ} \mathrm{C}$. Malt extract agar plates were incubated at $37^{\circ} \mathrm{C}$, the optimum temperature for A. fumigatus (Swan et al., 2002). Colonies growing on both media were enumerated visually after 3 to 14 days. The $95 \%$ confidence interval of micro-organisms dispersed in a solution was estimated using guidelines provided in the BS 5763 standard.

\subsection{SCREEN3 depletion curves}

Modelling the depletion of bioaerosols with distance downwind of a facility requires prior estimation of a bioaerosol flux. An estimation of the bioaerosol emission flux and construction of a depletion curve for static compost windrows is provided in Taha et al. (2005). For the active source term study, the approach of Dowd et al. (2000) was adopted, in which field analysis data was first used to backcalculate a flux rate at source using an airborne transport model, as there is no safe method of measuring the rate of release during agitation directly at $0 \mathrm{~m}$ (Taha et al., 2006a). Furthermore, as the passive releases tend to be from standard sized windrows, these were represented in the model as area sources. As the active releases tend to occur at a specific location within the facility, they were represented as point sources in SCREEN3. The full model parameters used in these experiments are provided in Table 1. 
Several simplifying and limiting assumptions are made in performing the modelling: (a) the particles displayed a Gaussian distribution in both lateral (crosswind) and vertical directions; (b) no gravitational deposition is assumed; (c) the source was assumed to be continuous; (d) the wind velocity and direction were constant over the modelled time and distance; (e) the modelled surface was relatively flat; (f) the effects of buildings were not taken into account; (g) the gravitational settling of particles was assumed to be negligible; (h) the particle and wind velocity were assumed to be the same; and (i) microbial inactivation was not considered. In the light of these substantial simplifications and methodological constraints, the results presented from the SCREEN3 model are likely to be highly conservative.

\subsection{ADMS 3 depletion curves}

The parameters and variables defined for the SCREEN3 modelling (Table 1) were used in ADMS 3.3, in order to provide a direct comparison between the two models. ADMS 3.3 was employed to address some of the simplifying assumptions used during SCREEN3 modelling. Several ADMS 3.3 experiments were undertaken. The first replicated the SCREEN3 modelling, using the pre-defined stability classes and modelling each source separately. The second set of experiments modelled the sources as a group, producing a combined output for the facility as a whole. These experiments were repeated for both organisms measured (actinomycetes and Aspergillus fumigatus), and for the active and passive samples. The passive emission rates were modelled as area sources, to represent the windrows. As the active samples were taken at a point near the agitation activity, these are modelled as point sources.

\section{Results and discussion}


Bioaerosol concentrations measured using the wind tunnel and directly above the compost pile (passive emissions) are presented in Figure 1 and 2. Bioaerosol concentrations and the estimated emission rates downwind from the various processing activities are presented in Table 1 and Figure 3. The source depletion curves constructed for the passive emissions are presented in Figure 4 (Aspergillus fumigatus) and Figure 5 (actinomycetes). Similarly, the source depletion curves for the active emissions are shown in Figures 6 and 7. The results of the combined sources modelling using ADMS 3.3 are presented in Figures 8 to 11.

\subsection{Bioaerosol concentrations (static emissions)}

The concentration of Aspergillus fumigatus measured within the facility ranged between $10^{3}$ and $10^{4} \mathrm{cfu} / \mathrm{m}^{3}$ (Figure 1). The concentration of actinomycetes was within a similar range, with a higher maximum concentration $\left(10^{3}\right.$ to $\left.10^{5} \mathrm{cfu} / \mathrm{m}^{3}\right)$. The bioaerosol concentrations measured with the wind tunnel did not reveal a distinct trend as the compost aged (Figure 1). It is therefore not possible to state that emissions will increase or decrease as compost ages, based on these results. However, the measurement of air directly above the compost pile $(0.3 \mathrm{~m})$ showed a higher bioaerosols concentration at the early stage of composting, which gradually reduced over the 16 weeks (Figure 2). However the concentration increased when the compost age was 16 weeks, which we believe may be due to different weather conditions or drying of the compost. These readings indicated the presence of significant amounts of bioaerosols in air close to the surface of the compost pile, under static conditions, compared to a typical background concentration of $1000 \mathrm{cfu} / \mathrm{m}^{3}$ (Wheeler et al., 2001).

The specific bioaerosol emission rates (SBERs) estimated ranged from $100 \mathrm{cfu} / \mathrm{m}^{2} / \mathrm{s}$ to $1200 \mathrm{cfu} / \mathrm{m}^{2} / \mathrm{s}$ for all samples in which bioaerosols were detected. This range is lower by 
one log than the SBERs of $8000-22000 \mathrm{cfu} / \mathrm{m}^{2} / \mathrm{s}$ measured by Taha et al. (2006a) at a full scale commercial facility. The contributing factors to this difference are the buildings that reduce emissions and the ambient wind velocity, as research has shown that higher wind velocities are required to release bioaerosols (McCartney, 1994; Tay et al., 2001). At this study site, the wind velocity average was $0.3 \mathrm{~m} / \mathrm{s}$ (due to the covered nature of the facility which reduces the wind velocity inside the boundaries) whereas Taha et al. (2006a) measured an ambient wind velocity of $1 \mathrm{~m} / \mathrm{s}$. This is shown when the SBER inside the wind tunnel and the SBER with the ambient wind velocity are compared. Taha et al. (2006a) found SBERs of $1100-4000 \mathrm{cfu} / \mathrm{m}^{2} / \mathrm{s}$ inside the wind tunnel and 100 to $1100 \mathrm{cfu} / \mathrm{m}^{2} / \mathrm{s}$, with the ambient wind velocity.

\subsection{Bioaerosol concentrations (dynamic emissions)}

The dynamic release of bioaerosols was assessed by estimating the bioaerosol emission rate during different activities and for different compost ages. The activities studied here were shredding, turning and screening of the compost, similar to those studied by Taha et al. (2006a). In addition, the emission rate from a windrow turner is estimated. The concentration of bioaerosols measured at $c a .5-10 \mathrm{~m}$ from agitation activities are shown in Figure 3. The concentrations generally range between $10^{4}$ and $10^{5} \mathrm{cfu} / \mathrm{m}^{3}$. However concentrations as low as $10^{3} \mathrm{cfu} / \mathrm{m}^{3}$ and as high as $10^{6} \mathrm{cfu} / \mathrm{m}^{3}$ were also measured. These concentrations are at least 1-log higher than those recorded for the passive releases and support the suggestion by Taha et al. (2006a) that the agitation activities are the main sources for these operational, episodic emissions. It is also important to note that turning, either by front-end loader or windrow turner, is a non-stationary activity and it is not possible to sample the emissions directly at source. 
From the measurement data for the agitation activities (Figure 3), the emission rate was then estimated using the SCREEN3 air dispersion model (Table 2). Turning at this site recorded maximum emission rates between $10^{4}$ and $10^{7} \mathrm{cfu} / \mathrm{s}$, with the maximum reading being 2-log lower than that estimated by Taha et al. (2006a).

The results show no significant emission rate differences between different ages of compost pile. However, there is a significant difference between activities, with front-end loader turning emitting the most bioaerosols, followed by windrow turner, screening and finally shredding. Turning at the early stage of composting releases higher bioaerosols compared with the later stages. During the first weeks, the bioaerosols release rate during turning was between $10^{4}$ and $10^{7} \mathrm{cfu} / \mathrm{s}$, compared with $10^{4}$ to $10^{6} \mathrm{cfu} / \mathrm{s}$ for the turning of compost age from 4 weeks to 16 weeks. This is further evidence of the gradual release of bioaerosols as compost ages detected by the passive sampling described above.

\subsection{Depletion curves}

The source depletion curves generated for the passive and active releases (Figures 4 to 7) display a similar trend to analysis conducted by Taha et al. (2006a). The Environment Agency guidance (Environment Agency, 2004) suggests that a typical background concentration that can be used for comparison is $10^{3} \mathrm{cfu} / \mathrm{m}^{3}$. As the upwind readings for this site showed a "no reading", we will compare the modelled concentrations to the $10^{3} \mathrm{cfu} / \mathrm{m}^{3}$ level. For the passive releases, the bioaerosol concentration is estimated to be reduced to this level at a distance of approximately $100 \mathrm{~m}$ for Aspergillus fumigatus and $200 \mathrm{~m}$ for actinomycetes. The agitation activities produce emissions of at least 1-log higher than the passive emissions. Despite this, all active bioaerosol emissions were estimated to be reduced to background levels at a distance of less than 100m. The Environment Agency requires a risk assessment to be undertaken for any composting facility that has a sensitive receptor 
within $250 \mathrm{~m}$ of its boundary. The results presented here suggest that bioaerosol concentrations from both active and passive emissions will reduce to below typical background levels before reaching the $250 \mathrm{~m}$ risk assessment requirement threshold.

Analysis of the figures reveals the differences between the two dispersion models used to estimate the source depletion curves. SCREEN3, the screening-level model is shown to be more conservative in its estimation than the advanced ADMS dispersion model. This is most likely due to the inclusion of an alternative mixing height algorithm (Brode, 1991), which uses the maximum of a predetermined mixing height or a value adjusted slightly higher than the plume height, based on stability class. The use of this alternative algorithm results in concentrations that are more conservative that the USEPA's full Gaussian dispersion model, ISCST3 (USEPA, 1996). We therefore expect SCREEN3 results to be more conservative when compared with another advanced Gaussian-like model such as ADMS 3.3.

ADMS predicts that the concentrations will decrease from 0m, while SCREEN3 predicts an initial increase in concentrations for the passive emissions only, with the maximum concentration occurring at approximately 40m from the source. This may be due to the different source types used in this study. The passive releases were modelled as area sources, to reflect the entire compost windrow, while the active releases were modelled as point sources, as by their nature these activities tend to occur at a single point within the facility.

The ADMS dispersion model has the added capability of modelling more than one source. This provides a more realistic representation of dispersion from the facility, as each facility is likely to have several windrows of different ages on site at a single time, along with the possibility of at least one activity (shredding, screening or turning) occurring each day of operation. Figures 8 (A. fumigatus) and 9 (actinomycetes) show the depletion curves 
predicted by ADMS for three different dates based on the combined passive sources sampled on that day. The concentration on all three days reduces to less than background concentration before the 250m Environment Agency threshold for risk assessments. For $A$. fumigatus, the maximum concentration is below the background level of $10^{3} \mathrm{cfu} / \mathrm{m}^{3}$. The concentrations predicted are also not significantly higher than those for the single sources, which could be due to the spacing of the sources within the model's output grid.

Figures 10 and 11 show the source depletion curves for the combined active and passive emissions for the three dates. The maximum concentrations are now within the range of $10^{4}-10^{5} \mathrm{cfu} / \mathrm{m}^{3}$, which shows that the active emissions are the main source of bioaerosols at these composting facilities. Despite these initial high concentrations, the depletion curves again show that concentrations reach typical background levels within the $250 \mathrm{~m}$ threshold for risk assessments.

\subsection{Discussion}

The source depletion curves presented are still considered conservative due to the clumping tendency of bioaerosol (physical decay) and deactivation (biological decay) caused by sunlight and heat. Although the clumping tendency of bioaerosols has been discussed in regards to their dispersion (e.g. Wheeler et al., 2001), there is little published research data to support any conclusions regarding this tendency, particularly in association with composting facilities. Previous literature suggests that fungal spores often form clumps when aerosolized (e.g. Lacey, 1991; Trunov et al., 2001), and that these clumps are within respirable size (Karlsson and Malmberg, 1989). The same study has found that clumping was more distinct for actinomycetes. Wider research has examined the tendency of bacteria and fungi to form clumps in media other than air, such as water and soil (Calleja et al., 1984). 
Given the limited information regarding aggregation within air, we can only infer the possible characteristics that may be required for bioaerosols to form clumps, based on the existing literature. The literature suggests that random collision (Calleja et al., 1984) and faster air velocities (> $0.3 \mathrm{~cm} / \mathrm{s}$ ) are needed to form aerobic clumps (Tay et al., 2001). The agitation activities that occur at composting facilities (e.g. shredding, turning and screening) produce sufficient air turbulence to result in random collisions of bioaerosols. Tay et al. (2001) also show that increasing temperatures are likely to increase clumping, suggesting that the high temperatures generated within compost windrows may encourage bioaerosol aggregation above piles, particularly during the more active stages of composting. However, further research would be necessary to confirm this suggestion.

The mechanisms behind microbial clumping are linked with the physicochemical properties of the microbial cells such as surface hydrophobicity and charges on cell walls (Borrego et al., 2000; Dufrêne, 2000; Amanullah, 2001). Bush and Stumm (1968) reveal that, within the $\mathrm{pH}$ range of 5 to 9 , bacteria have a net negative charge. The $\mathrm{pH}$ within composting piles is usually between 6 and 8.5, within this range. Clumps may therefore result from this negative charge attracting positively charged cell products. It is therefore important to begin taking the tendency of bioaerosols to form aggregations into account when predicting their dispersal, as current risk assessments are likely to be over-conservative as a result. Future work will aim to mimic clumping tendencies when using the advanced modelling functions in ADMS 3.3, such as the deposition options.

Bioaerosol viability also requires consideration because studies have shown that nonviable cell wall components, such as endotoxins, may cause adverse health effects (Castellan et al., 1987; Kennedy et al., 1987; Eduard, 1993; Eduard, 2001; Lange et al., 2003). The actual fungal cells whether viable or not can prompt an allergenic response. Traditional monitoring methods capture air samples and then culture the viable bioaerosols from the 
sample. Some of these sampling methods (impaction and impingement) are known to impose significant stress on micro-organisms (Lin et al, 2000) and Górny et al. (2002) show that a significant proportion of bioaerosols released are considerably smaller than the spores released from surfaces contaminated with fungi. This might suggest that the non-viable components may be more numerous than the viable components, and that most published bioaerosol concentrations are underestimates of the true emissions. However, the practical difficulties associated with field sampling of bioaerosol components means that data to support this suggestion is not available. Given that dose-response relationships for bioaerosols, are currently not well defined, it would appear prudent for the $250 \mathrm{~m}$ threshold to remain in place until further evidence is available regarding the dispersal of non-viable bioaerosol components.

Jones and Harrison (2004) show that meteorological factors (temperature, humidity and solar radiation) effect the dispersal of the airborne micro-organisms, as well as their initial release. Elevated levels of fungi within buildings are also associated with higher temperatures and high humidity (Wan and Li, 1998). In addition, solar radiation has been shown to decrease the viability of bioaerosols (Ulevičius et al, 2000). It is generally accepted that composting windrows have a high humidity and high temperature, and are excellent environments for bioaerosols to proliferate. However, when considering their dispersal, little work has been done to examine the impact of the ambient environment on bioaerosol viability post-release, partly due to the complications involved in measuring non-viable bioaerosols in the field. Dust measurement and particle size ranges would have helped in supporting these results, and future work will aim to take this into account using field studies and by exploring the advanced options available in the ADMS 3.3 model.

\section{Conclusions and future work}


We have presented data demonstrating the ability to measure the concentration of bioaerosols emitted 'at source' during static conditions and for agitation activities, from compost of different ages. From these results, we have estimated the emission flux of bioaerosols from compost processing activities, using a simple screening-level dispersion model and a more advanced new generation dispersion model. We have previously concluded that agitation activities result in releases of bioaerosols in the order of two to three log higher than from static compost windrows (Taha et al., 2006a). The results presented here add further weight to this conclusion. In addition, we have shown that:

- the age of the compost has little effect on the bioaerosols emitted;

- the simple screening-level model SCREEN3 provides a conservative estimate of the source depletion curves of viable bioaerosol emissions;

- $\quad$ the more advanced new generation model, ADMS 3.3 can be used to estimate bioaerosol dispersal from composting facilities;

- the source depletion curves estimated by both models can still be considered as only conservative estimate of bioaerosol dispersal, as both models are currently not able to take into account bioaerosol properties such as clumping and inactivation.

Future work will focus on improving measurement techniques for monitoring bioaerosol emissions, focussing on the clumping and inactivation properties. Further studies will be undertaken to examine the more advanced options within ADMS 3.3 in order to improve the dispersion modelling techniques. This research will further improve the science behind current bioaerosol risk assessment methodologies.

\section{Acknowledgements}



seconded to Cranfield University through the Malaysian Continuing Professional Development Scheme. AT is sponsored by an EPSRC doctoral training award. GHD is an

4 Environment Agency supported Postdoctoral Fellow (Science Project P1-514). We

5 acknowledge the technical support of Dr Martin Lowe, Visiting Fellow, Integrated Waste

6 Management Centre; Mike Smith and Dr Nina Sweet of the Environment Agency and Dr

7 David Aldred, Ester Baxter and Professor Naresh Magan of Cranfield University. The opinions expressed are those of the authors' alone. 


\section{References}

ADAS/SWICEB, 2005. Bioaerosol monitoring and dispersion from composting sites. SWICEB report, August 2005.

Amanullah, A., Leonildi, E., Nienow, A.W., and Thomas, C.R., 2001. Dynamics of mycelial aggregation in cultures of Aspergillus oryzae. Bioprocess and Biosystems Engineering, 24, 101-107.

Borrego, S., Niubo, E., Ancheta, O., and Espinosa, M.E., 2000. Study of microbial aggregation in Mycobacterium using image analysis and electron microscopy. Tissue Cell, 32(6), 494-500.

Brode, R.W., 1991. A Comparison of SCREEN Model Dispersion Estimates with Estimates From a Refined Dispersion Model. Seventh Joint Conference on Applications of Air Pollution Meteorology with A\&WMA., 93-96.

Calleja, G.B., Atkinson, B., Reichenbach, H., Garrod, D.R., Rose, A.H., Hirsch, P., Schink, B., Jenkins, D., Vincent, B., Johnson, B.F., and Wildner, P.A., 1984. Aggregation. In Marshall, K.C. (ed.) Microbial adhesion and aggregation. Dahlem Konferenzen, Springer-Verlag, Berlin, pp.95-107.

Carruthers, D.J., Holroyd, R.J., Hunt, J.C.R., Weng, W.S., Robins, A.G., Apsley, D.D., Thompson, D.J., and Smith, F.B., 1994. UK-ADMS: A new approach to modelling dispersion in the earth's atmospheric boundary layer. Wind Engineering and Industrial Aerodynamics, 52,139-153.

Castellan, R.M., Olenchock, S.K., Kinsley, K.B., and Hankinson, J.L., 1987. Inhaled endotoxin and decreased spirometric values. Am. Ind. Hyg. Assoc., 317, 605-610. CERC, 2003. ADMS 3 Technical Specification. Cambridge Environmental Research Consultants. 
Danneberg, G., Grueneklee, E., Seitz, M., Hartung, J., and Driesel, A.J., 1997. Microbial and endotoxin imissions in the neighbourhood of a composting plant. Annals of Agricultural and Environmental Medicine, 4(1), 169-173.

Douwes, J., Thorne, P., Pearce, N. and Heederik, D., 2003. Review: Bioaerosol health effects and exposure assessment: Progress and prospects. Annals of Occupational Hygiene, 47(3), 187-200.

Dowd, E.S., Gerba, C.G., Pepper, I.L., and Pillai, S.D., 2000. Bioaerosol transport modelling and risk assessment in relation to biosolid placement. Journal of Environmental Quality, 29(1), 343-348.

Dufrêne, Y.F., 2000. Direct characterization of the physicochemical properties of fungal spores using functionalised AFM probes. Biophysical Journal, 78(6), 3286-3291.

Eduard, W., Sandven, P., and Levy, F., 1993. Serum IgG antibodies to mold spores in two Norwegian sawmill populations: relationship to respiratory and other work-related symptoms. Am. J. Ind. Med., 24, 207-222.

Eduard, W., Douwes, J., Mehl, R., Heedrik, D., and Melbostad, E., 2001. Short term exposure to airborne microbial agents during farm work: exposure-response relations with eye and respiratory symptoms. Occup. Environ. Med., 58, 113-118.

Environment Agency, 2002. Processes and Plant for Waste Composting and other Aerobic Treatment, R\&D Technical Report P1-311/TR, Environment Agency, Bristol, 198pp.

Environment Agency, 2004. An Environmental Risk Management Framework for Composting Facilities in England and Wales, Environment Agency internal guidance prepared by Pollard, S., Tyrrel, S. and Longhurst, P. (Cranfield University), Version 1.0, October 2004, Environment Agency, Bristol, 41pp. 
Górny, R.L., Reponen, T., Willeke, K., Schmechel, D., Robine, E., Boissier, M., and Grinshpun, S.A., 2002. Fungal fragments as indoor air biocontaminants. Applied and Environmental Microbiology, 68(7), 3522-3531.

Hanna, S.R., Egan, B.A., Purdum, J., and Wagler, J., 2000. Evaluation of the ADMS, AERMOD and ISC3 dispersion models with the Optex, Duke Forest, Kincaid, Indianapolis, and Lovett field data sets. International Journal of Environment and Pollution, 16(1-6), 301-314.

Henningson, E.W., and Ahlberg, M.S., 1994. Evaluation of microbiological aerosol samplers: a review. Journal of Aerosol Science, 25(8), 1459-1492.

Jiang J. and Kaye R., 2001. Sampling techniques for odour measurement. Odour in Wastewater Treatment: Measurement, Modeling and Control, p. 95-119.

Jones, A.M., and Harrison, R.M., 2004. The effects of meteorological factors on atmospheric bioaerosol concentrations - a review. Science of the Total Environment, 326, 151-180.

Karlsson, K., and Malmberg, P., 1989. Characterization of exposure to molds and actinomycetes in agricultural dusts by scanning electron microscopy, fluorescence microscopy and the culture method. Scan. J. Work Environ. Health, 15, 353-359.

Kennedy, S.M., Christiani, D.C., Eisen, E.A., Wegman, D.H., Greaves, I.A., Olenchock, S.A., Ye, T., and Lu, P., 1987. Cotton dust and endotoxin exposure-response relationships in cotton textile workers. Am. Rev. Respir. Dis., 135, 194-200.

Lacey, J., 1991. Aggregation of spores and its effect on aerodynamic behaviour. Grana, 30, 437-445.

Lange, J.H., Mastrangelo, G., Fedeli, U., Fadda, E., Rylander, R., and Lee, E., 2003. Endotoxin exposure and lung cancer mortality by type of farming: is there a hidden doseresponse relationship? Annals of Agricultural and Environmental Medicine, 10, 229-232. 
Lighthart, B., and Mohr, A.J., 1987. Estimating downwind concentrations of viable airborne microorganisms in dynamic atmospheric conditions. Applied Environmental Microbiology., 53(7), 1580-1383.

Lin, X., Reponen, T., Willeke, K., Wand, Z., Grinshpun, S.A., and Trunov, M., 2000. Survival of airborne microorganisms during swirling aerosol collection. Aerosol Science and Technology, 32, 184-196.

Martinez, K.F., Rao, C.Y., and Burton, N.C., 2004. Exposure assessment and analysis for biological agents. Grana, 43, 193-208.

Millner, P.D., Bassett, D.A., and Marsh, P.B., 1980. Dispersal of Aspergillus fumigatus from sewage sludge compost piles subjected to mechanical agitation in open air. Appl. Environ. Microbiol., 39(5), 1000-1009.

Palmgren, U., Strom, G., Blomquist, G. and Malmberg, P., 1986. Collection of airborne micro-organism on Nuclepore filters estimation and analysis- CAMNEA method. J. Applied Bacteriology, 61, 401-406.

Pollard, S.J.T., Smith, R., Longhurst, P.J., Eduljee, G. and Hall, D., 2006. Recent developments in the application of risk analysis to waste technologies, Environment International, in press

Sanches-Monedero, M.A. and Stentiford, E.I., 2003. Generation and dispersion of airborne microorganisms from composting facilities. IChemE, 81(B3), 166-170.

Swan, J.R., Crook, B. and Gilbert, E.J., 2002. Microbial emissions from composting sites. In Environmental and Health Impact of Solid Waste Management Activities, Issues in Environmental Science and Technology, No. 18, The Royal Society of Chemistry, 73101. 
Swan, J.R., Kelsey, A., Crook, B., and Gilbert, E.J., 2003. Occupational and environmental exposure to bioaerosols from composts and potential health effects - a critical review of published data. Health and Safety Executive Research Report 130, ISBN 0717627071.

Taha, M.P.M., Drew G.H., Longhurst P.J., Smith R. and Pollard S.J.T, 2006a. Bioaerosol releases from compost facilities: evaluating passive and active source terms at a green waste facility for improved risk assessments. Atmospheric Environment, 40, 1159-1169.

Taha M.P.M., Pollard, S.J.T., Sarkar, U. and Longhurst, P., 2005. Estimating fugitive bioaerosol release from static compost windrows: Feasibility of a portable wind tunnel approach. Waste Management, 24, 445-450.

Taha, M.P.M., Pollard, S.J.T., Sarkar, U. and Longhurst, P., 2004. The influence of process variable on bioaerosol emission flux and exposure-estimating fugitive bioaerosol release from static compost windrows. Proc. Biodegradable and Residual Waste Management, Harrogate, UK, 18-19 February, 2004, ISBN 0-9544708-1-8, 268-275.

Trunov, M., Trakumas, S., Willeke, K., Grinshpun, S.A., and Reponen, T., 2001. Collection of bioaerosol particles by impaction: effect of fungal spore agglomeration and bounce. Aerosol Science and Technology, 35, 617-624.

Tay, J.-H., Liu, Q.-S., and Liu, Y., 2001. The effects of shear force on the formation, structure and metabolism of aerobic granules. Applied Microbiol. Biotechnology, 57, 227-233.

Ulevičius, V., Pečiulytė, D., Mordas, G., and Lugauskas, A., 2000. Field study on changes in viability of airborne fungal propagules exposed to solar radition. Journal of Aerosol Science, 31(S1), S961-S962.

USEPA, 1995. SCREEN3 Model User's Guide. EPA-454/B-95-004. US Environmental Protection Agency, Research Triangle Park, NC. 
USEPA, 1996. SCREEN3 Model Change Bulletin. 12 February 1996. US Environmental Protection Agency, Research Triangle Park, NC. Available online at http://www.epa.gov/scram001/mcbs/scrz2.txt.

4

Wan, G.H., and Li, C.S., 1998. Indoor endotoxin and glucans in association with sick building syndrome. Journal of Aerosol Science, 29(S1), S1309-S1310.

6 Wheeler P.A., Stewart, I., Dumitrean, P. and Donovan, B., 2001. Health effects of composting: A study of three compost sites and review of past data. R \& D Technical Report P1-315/TR, Environmental Agency, Bristol, UK 


\section{Figure Captions}

Fig. 1 The bioaerosols concentration measured at mixing chamber of wind tunnel during surface flux analysis.

Fig. 2 Bioaerosols concentration measured in the air at about $300 \mathrm{~mm}$ from a surface of different compost pile ages.

Fig. 3. Bioaerosols concentration at $5 \mathrm{~m}, 10 \mathrm{~m}$ and $30 \mathrm{~m}$ measured while agitation activities were taking place

Fig 4. Source depletion curves of Aspergillus fumigatus from passive emissions estimated using the SCREEN3 and ADMS dispersion models

Fig 5. Source depletion curves of actinomycetes from passive emissions estimated using the SCREEN3 and ADMS dispersion models

Fig 6. Source depletion curves of Aspergillus fumigatus from agitation activities estimated using the SCREEN3 and ADMS dispersion models

Fig 7. Source depletion curves of actinomycetes from agitation activities estimated using the SCREEN3 and ADMS dispersion models

Fig 8. Estimated depletion curves of Aspergillus fumigatus using the ADMS model for combined passive sources on three separate dates. 
1 Fig 9. Estimated depletion curves of actinomycetes using the ADMS model for combined passive sources on three separate dates.

3

4 Fig 10. Estimated depletion curves of Aspergillus fumigatus using the ADMS model for 5 combined active and passive sources on three separate dates.

6

$7 \quad$ Fig 11. Estimated depletion curves of actinomycetes using the ADMS model for combined active and passive sources on three separate dates.

9

10 Table Captions

Table 1: Model parameters used for the SCREEN3 modelling

Table 2: Estimated emission rates of agitation activities 
$1 \quad$ Table 1: Model parameters used for the SCREEN3 modelling

\begin{tabular}{|l|r|r|r|r|}
\hline \multirow{2}{*}{ Parameter } & \multicolumn{2}{|c|}{ SCREEN3 } & \multicolumn{2}{c|}{ ADMS } \\
\cline { 2 - 5 } & $\begin{array}{c}\text { Active } \\
\text { emissions }\end{array}$ & $\begin{array}{c}\text { Passive } \\
\text { emissions }\end{array}$ & $\begin{array}{c}\text { Active } \\
\text { emissions }\end{array}$ & $\begin{array}{c}\text { Passive } \\
\text { emissions }\end{array}$ \\
\hline Source type & Point & Area & Point & Area \\
\hline Source release height & - & $2 \mathrm{~m}$ & $0 \mathrm{~m}$ & $2 \mathrm{~m}$ \\
\hline Source length & - & $80 \mathrm{~m}$ & - & $80 \mathrm{~m}$ \\
\hline Source width & - & $20 \mathrm{~m}$ & - & $20 \mathrm{~m}$ \\
\hline Receptor height & $1.8 \mathrm{~m}$ & $1.8 \mathrm{~m}$ & $1.8 \mathrm{~m}$ & $1.8 \mathrm{~m}$ \\
\hline Stack height & $3 \mathrm{~m}$ & - & $3 \mathrm{~m}$ & - \\
\hline Stack diameter & $3 \mathrm{~m}$ & - & $3 \mathrm{~m}$ & - \\
\hline Roughness length & Rural & Rural & $0.1 \mathrm{~m}$ & $0.1 \mathrm{~m}$ \\
\hline Stability class & $\mathrm{A}$ & $\mathrm{A}$ & $\mathrm{A}$ & $\mathrm{A}$ \\
\hline Exit velocity & $0.2 \mathrm{~m}$ & - & $0.2 \mathrm{~m}$ & $0.3 \mathrm{~m}$ \\
\hline $\begin{array}{l}\text { Stack exit } \\
\text { temperature }\end{array}$ & $283 \mathrm{~K}$ & - & $15{ }^{\circ} \mathrm{C}$ & $15^{\circ} \mathrm{C}$ \\
\hline Buildings & No & No & No & No \\
\hline Complex terrain & No & No & No & No \\
\hline
\end{tabular}

3 Table 2: Estimated emission rates of agitation activities

\begin{tabular}{|c|c|c|c|c|c|}
\hline \multirow[t]{2}{*}{ Activity (location) } & \multirow{2}{*}{$\begin{array}{c}\text { Compost } \\
\text { age (weeks) }\end{array}$} & \multicolumn{2}{|c|}{ A. fumigatus } & \multicolumn{2}{|c|}{ Actinomycetes } \\
\hline & & $\begin{array}{c}\text { bioaerosol } \\
\text { concentration } \\
\left(\mathrm{x} 10^{3}\right. \\
\left.\mathrm{cfu}^{3} / \mathrm{m}^{3}\right)^{*}\end{array}$ & $\begin{array}{l}\text { Estimated } \\
\text { emission rate } \\
\text { (x } 10^{3} \mathrm{cfu} / \mathrm{s} \text { ) }\end{array}$ & $\begin{array}{c}\text { bioaerosol } \\
\text { concentration } \\
\left(\mathrm{x} 10^{3}\right. \\
\left.\mathrm{cfu} / \mathrm{m}^{3}\right)^{*}\end{array}$ & $\begin{array}{l}\text { Estimated } \\
\text { emission rate } \\
\left.\text { (x } 10^{3} \mathrm{cfu} / \mathrm{s}\right)\end{array}$ \\
\hline $\begin{array}{l}\text { Windrow turner }(1) \\
5 \mathrm{~m} \text { from source }\end{array}$ & 4 & 150 & 550 & 220 & 750 \\
\hline $\begin{array}{l}\text { Windrow turner (2); } \\
5 \mathrm{~m} \text { from source }\end{array}$ & 4 & 370 & 1360 & 1200 & 4500 \\
\hline $\begin{array}{l}\text { Turning } 1(\mathrm{~A}) ; 5 \mathrm{~m} \\
\text { from source }\end{array}$ & $1-2$ & 4200 & 15000 & 110 & 330 \\
\hline $\begin{array}{l}\text { Turning } 1(\mathrm{~B}) ; 5 \mathrm{~m} \\
\text { from source }\end{array}$ & $1-2$ & 4400 & 16000 & 1500 & 5400 \\
\hline $\begin{array}{l}\text { Turning } 2(\mathrm{~A}) ; 5 \mathrm{~m} \\
\text { from source }\end{array}$ & $1-2$ & 857 & 3200 & $<1$ & - \\
\hline $\begin{array}{l}\text { Turning } 2(\mathrm{~B}) ; 5 \mathrm{~m} \\
\text { from source }\end{array}$ & $1-2$ & 1900 & 7100 & 3000 & 11000 \\
\hline Turning 1 (A) & 4 & 32 & 340 & 100 & 1100 \\
\hline Turning 1 (B) & 4 & 40 & 420 & 180 & 1900 \\
\hline Turning $1(\mathrm{C})$ & 4 & $<1$ & - & 6 & 65 \\
\hline $\begin{array}{l}\text { Turning } 2(\mathrm{~A}) ; 10 \mathrm{~m} \text { at } \\
\text { outlet direction }\end{array}$ & 4 & 33 & 360 & 56 & 600 \\
\hline $\begin{array}{l}\text { Turning } 3(\mathrm{~A}) ; 10 \mathrm{~m} \text { at } \\
\text { outlet direction }\end{array}$ & 8 & 42 & 400 & 19 & 200 \\
\hline $\begin{array}{l}\text { Turning } 3(\mathrm{~B}) ; 10 \mathrm{~m} \text { at } \\
\text { outlet direction }\end{array}$ & 8 & 102 & 1100 & 96 & 1000 \\
\hline $\begin{array}{l}\text { Turning } 4(\mathrm{~A}) ; 10 \mathrm{~m} \text { at } \\
\text { outlet direction }\end{array}$ & 12 & 120 & 1200 & 53 & 560 \\
\hline $\begin{array}{l}\text { Turning } 4(\mathrm{~B}) ; 10 \mathrm{~m} \text { at } \\
\text { outlet direction }\end{array}$ & 12 & 190 & 2000 & 73 & 770 \\
\hline Shredding (1) & $1-3$ & 70 & 270 & 12 & 48 \\
\hline Shredding (2) & $1-3$ & 23 & 87 & 29 & 110 \\
\hline
\end{tabular}




\begin{tabular}{|l|r|r|r|r|r|}
\hline Screening (1) & 16 & 14 & 55 & 29 & 110 \\
\hline Screening (2) & 16 & 80 & 300 & 42 & 160 \\
\hline
\end{tabular}

$2 \quad * *$ the net concentration (minus background reading) is used for emission rate estimation. 


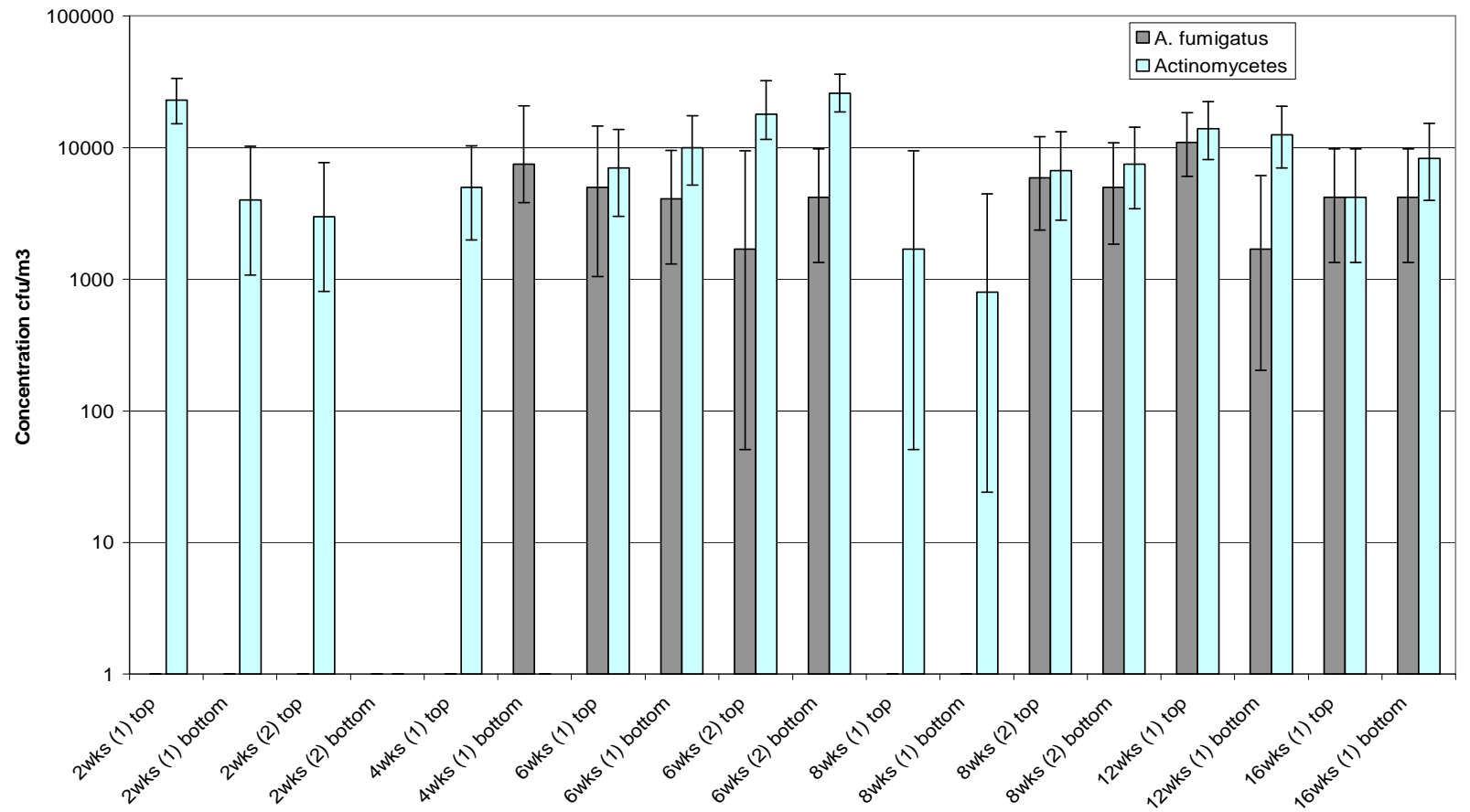

Fig. 1 The bioaerosols concentration measured in the mixing chamber of the wind tunnel during surface flux analysis.

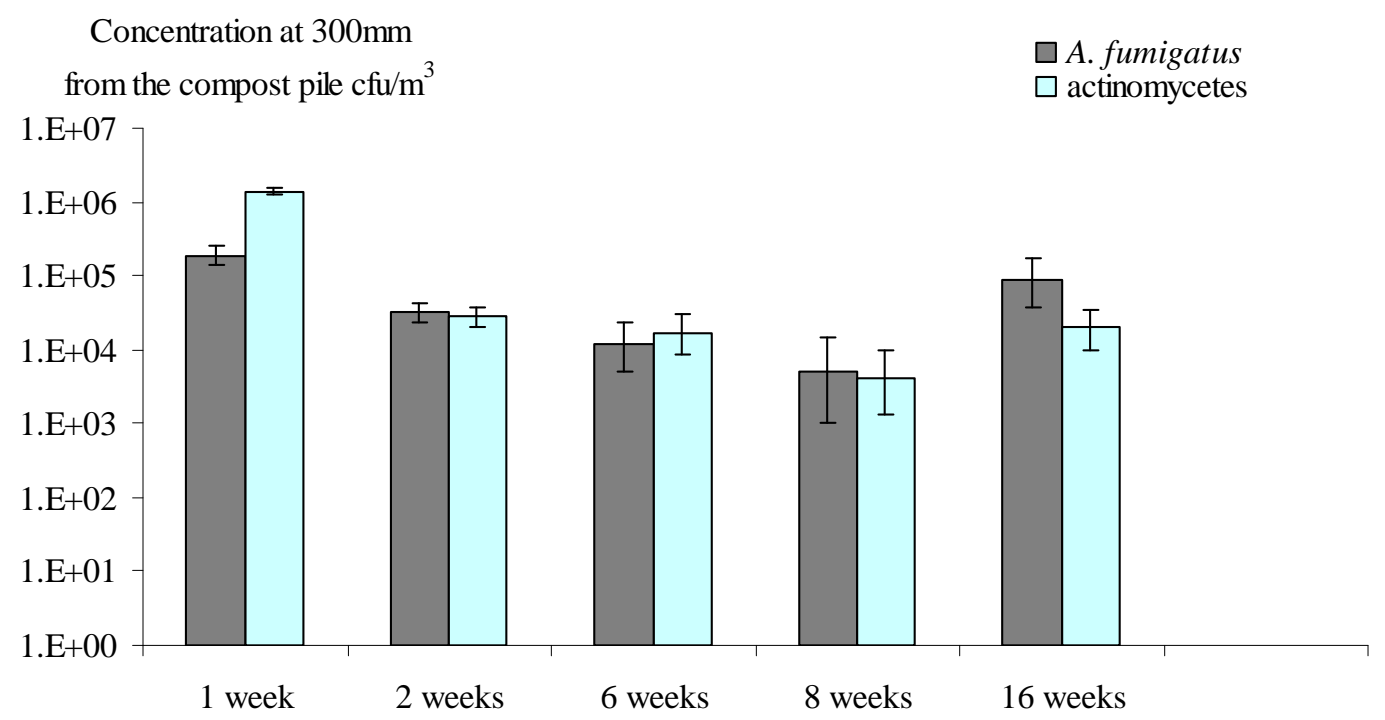

Fig. 2 Bioaerosols concentration measured in the air at about 300mm from a surface of different compost pile ages. 


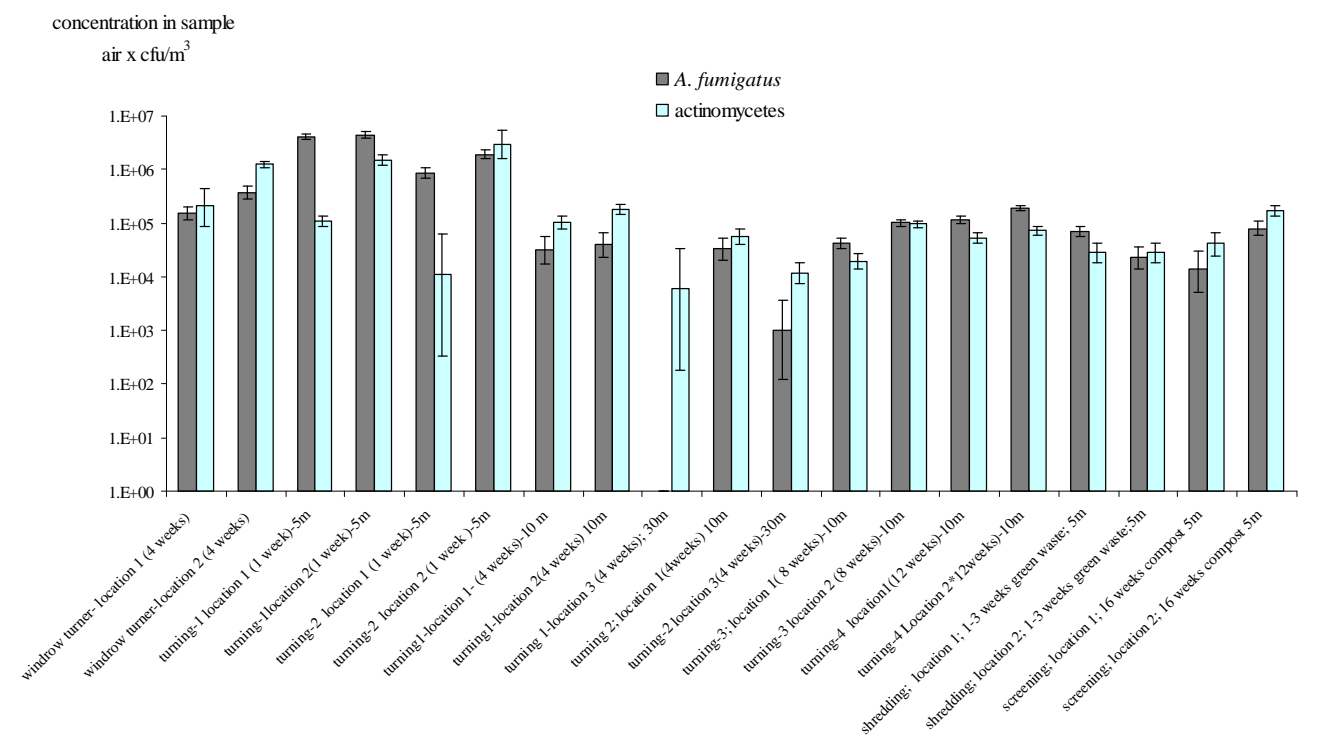

Fig. 3. Bioaerosols concentration at $5 \mathrm{~m}, 10 \mathrm{~m}$ and $30 \mathrm{~m}$ measured while agitation activities were taking place

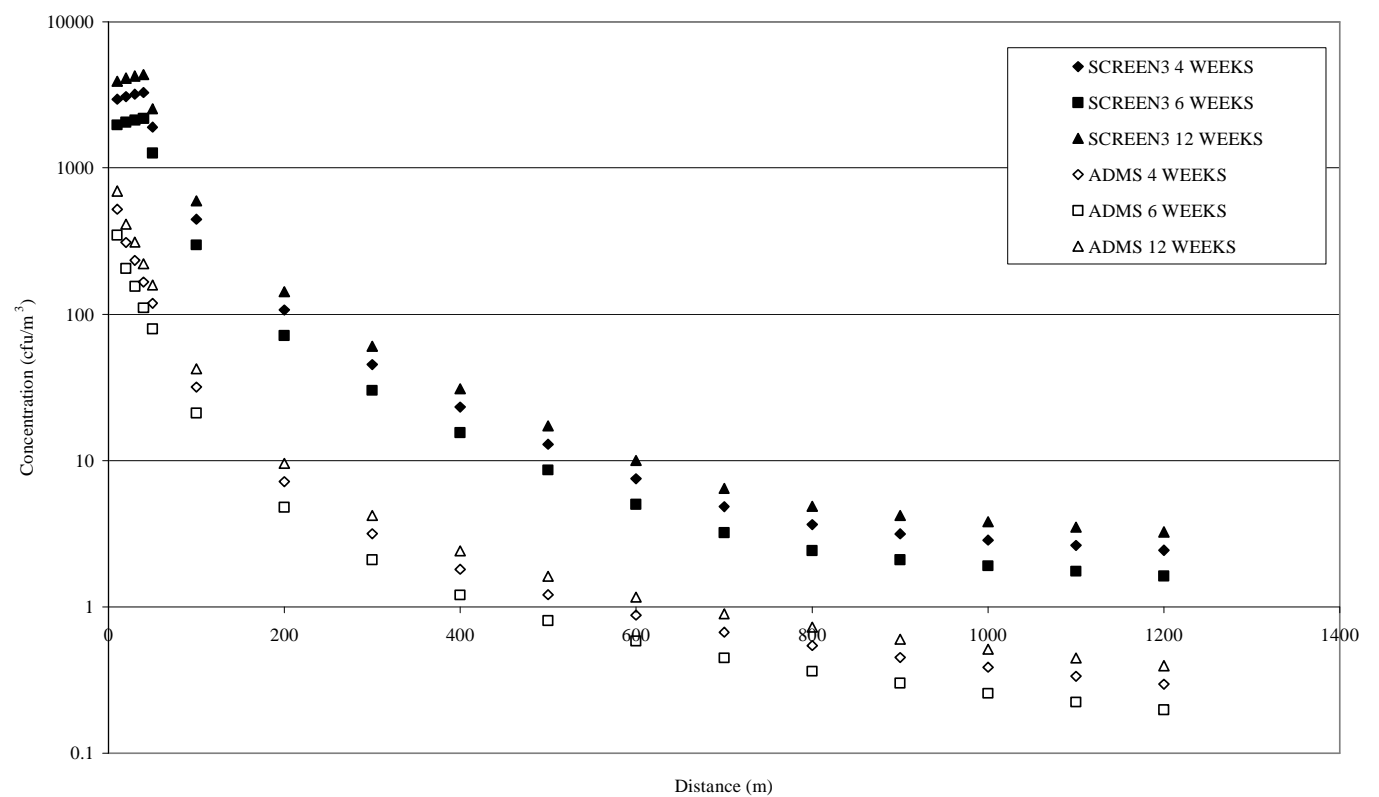

Fig 4. Source depletion curves of Aspergillus fumigatus from passive emissions estimated using the SCREEN3 and ADMS dispersion models 


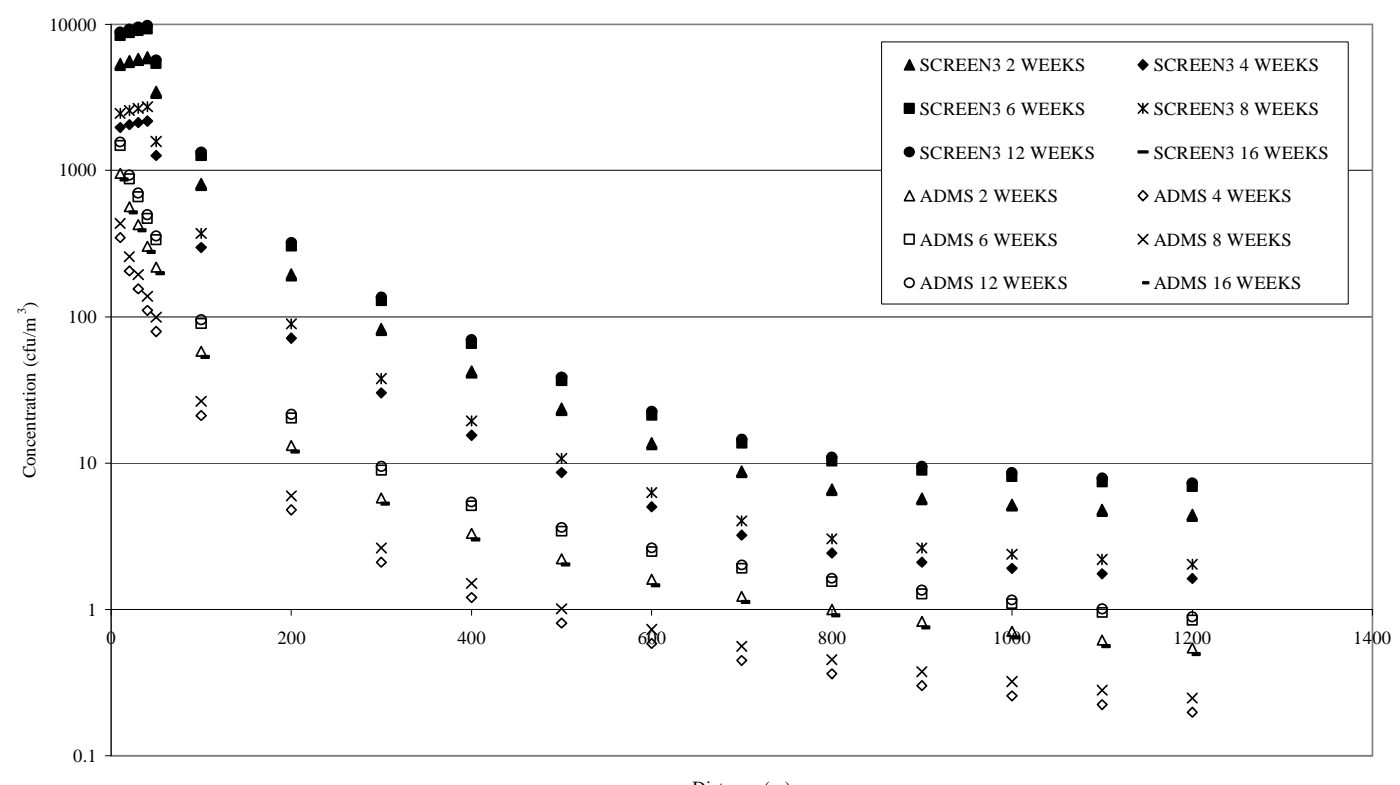

Distance (m)

Fig 5. Source depletion curves of actinomycetes from passive emissions estimated using the SCREEN3 and ADMS dispersion models

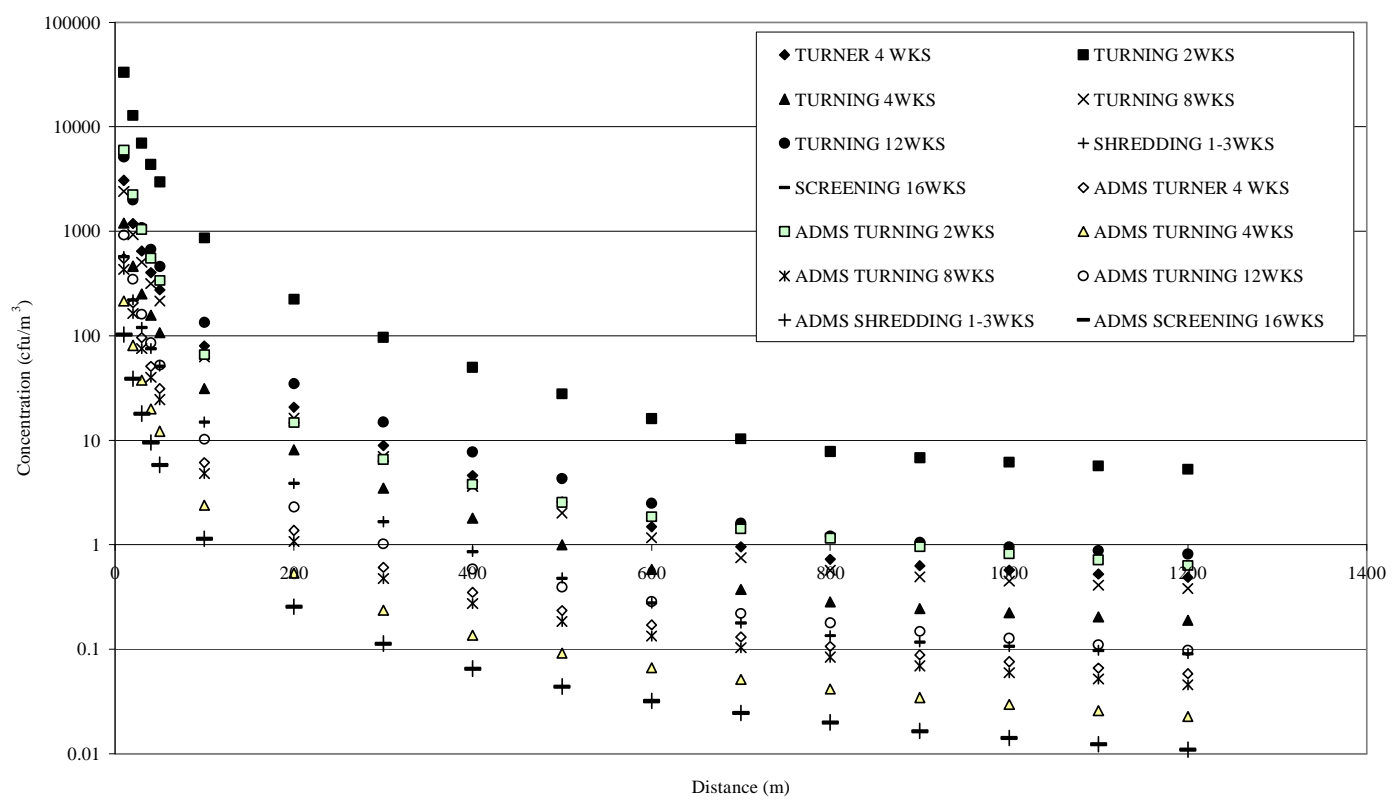

Fig 6. Source depletion curves of Aspergillus fumigatus from agitation activities estimated using the SCREEN3 and ADMS dispersion models 


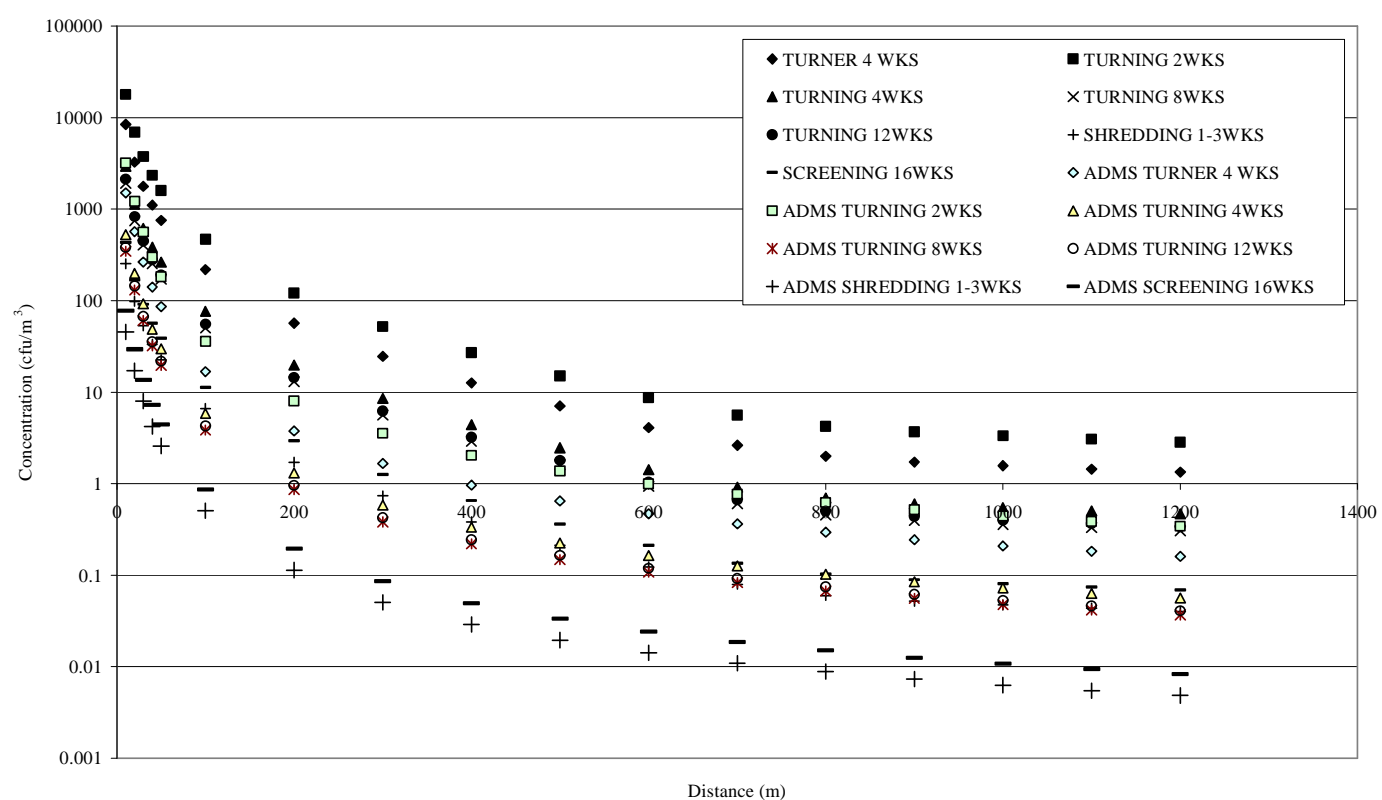

Fig 7. Source depletion curves of actinomycetes from agitation activities estimated using the SCREEN3 and ADMS dispersion models

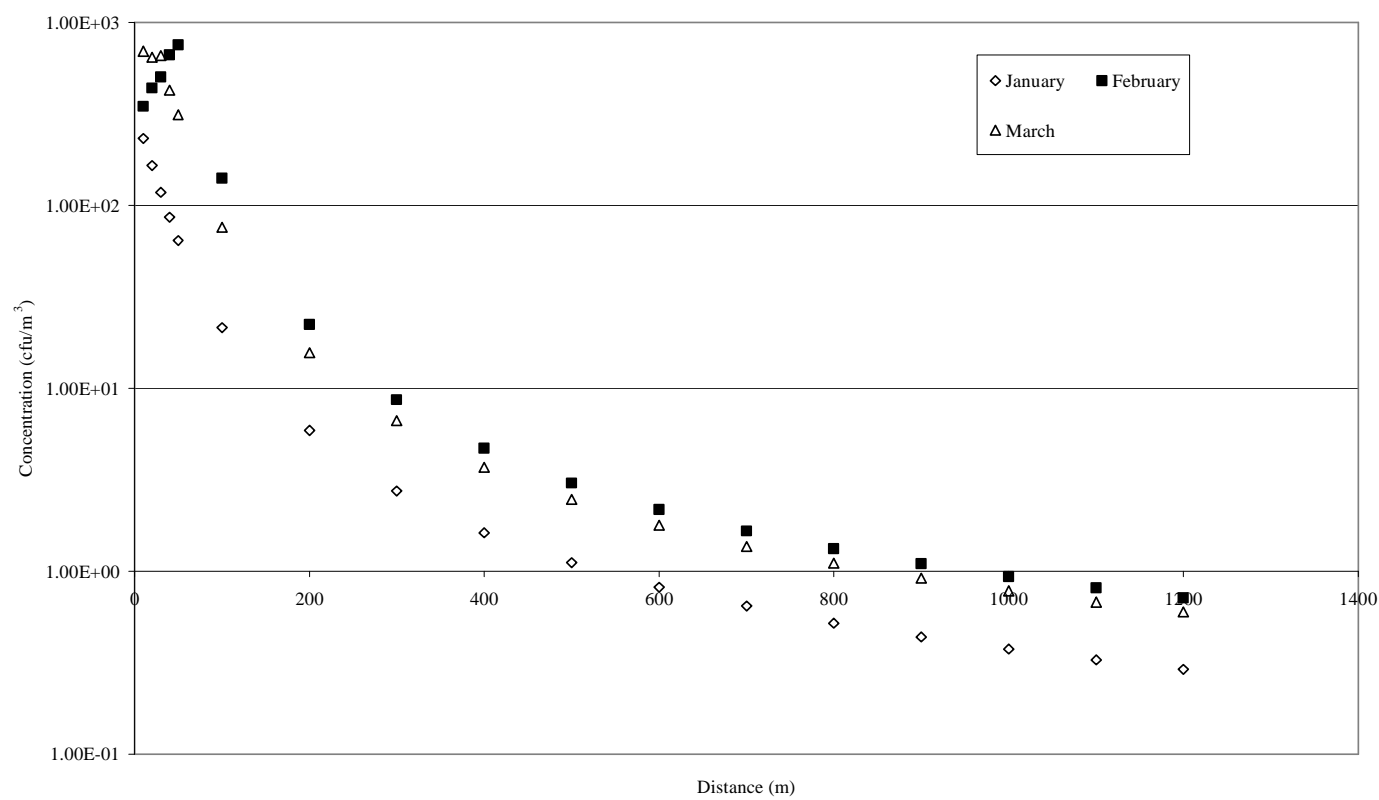

Fig 8. Estimated depletion curves of Aspergillus fumigatus using the ADMS model for combined passive sources on three separate dates. 


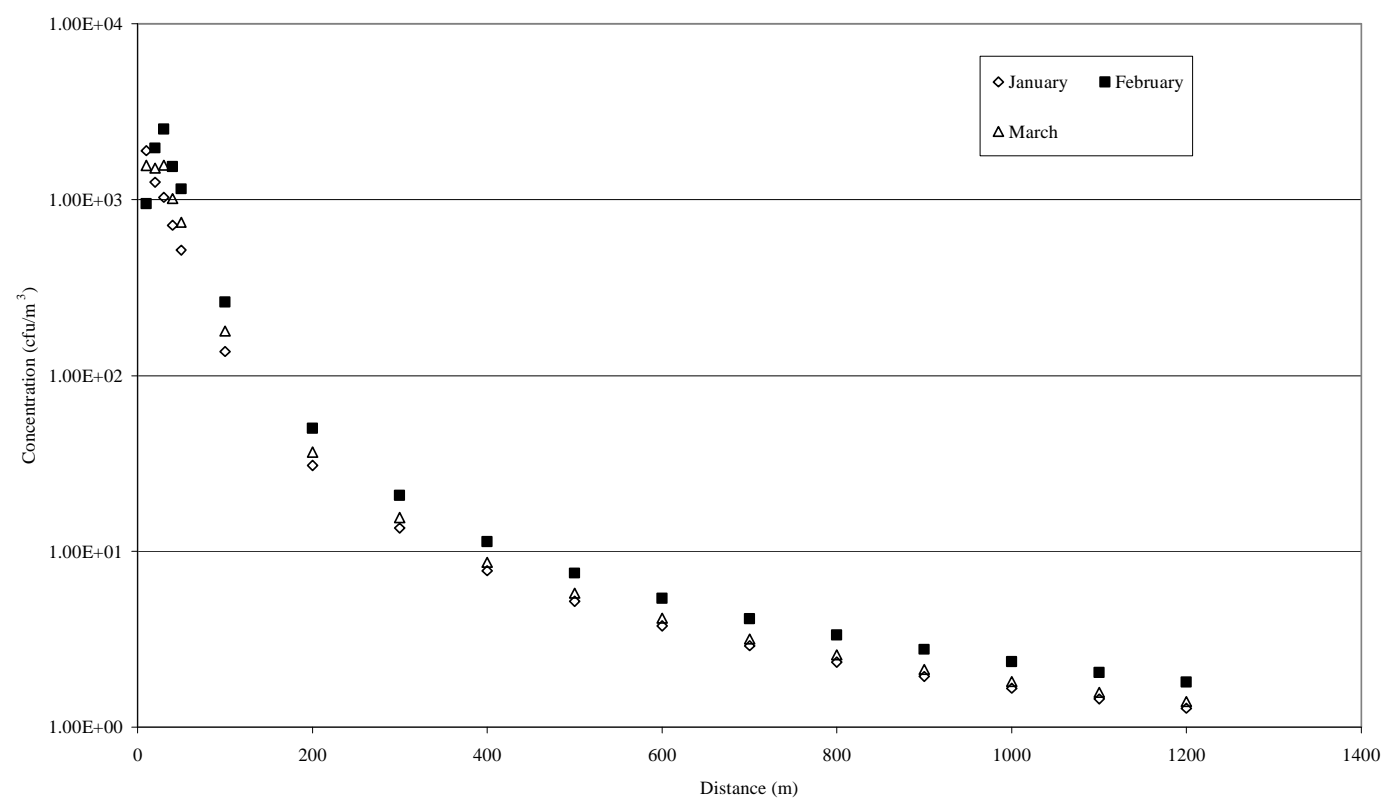

Fig 9. Estimated depletion curves of actinomycetes using the ADMS model for combined passive sources on three separate dates.

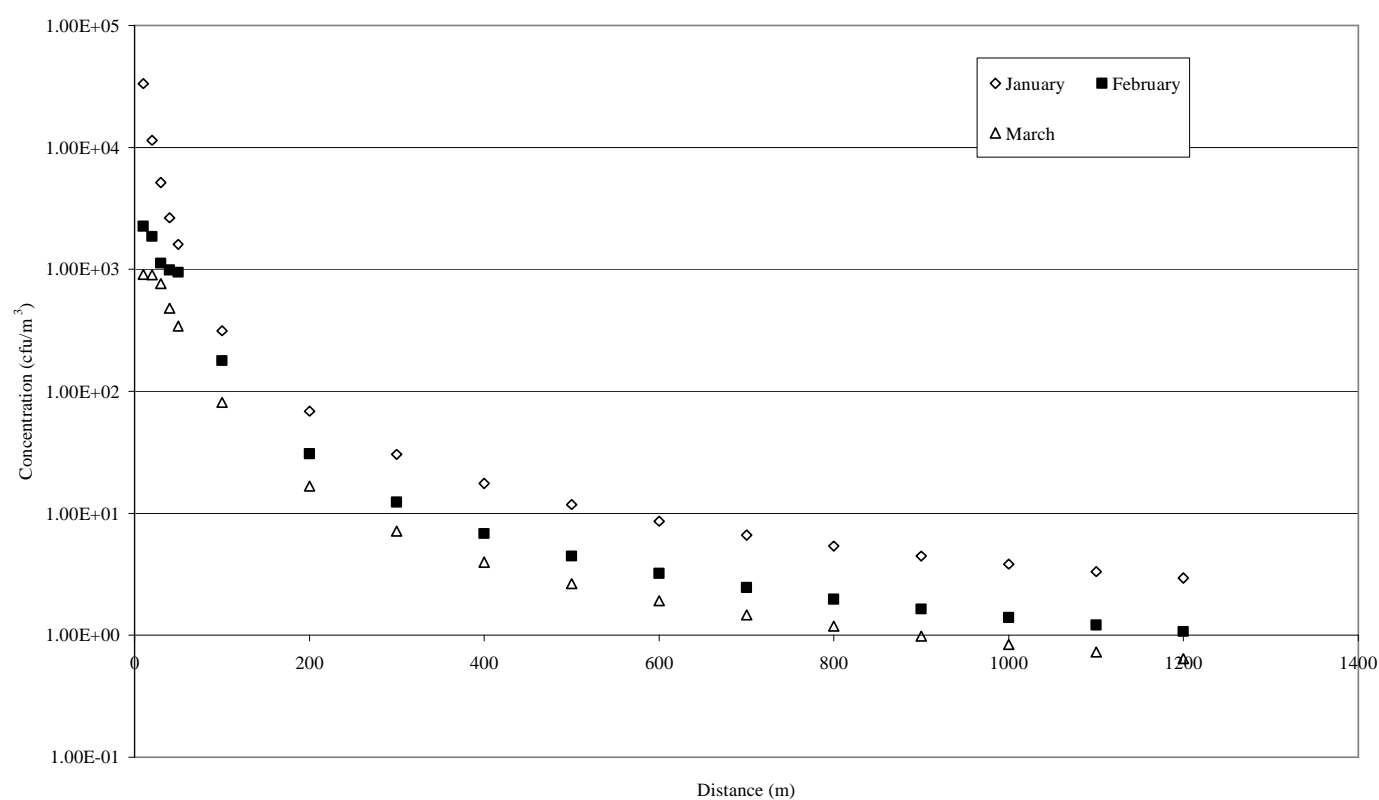

Fig 10. Estimated depletion curves of Aspergillus fumigatus using the ADMS model for combined active and passive sources on three separate dates. 


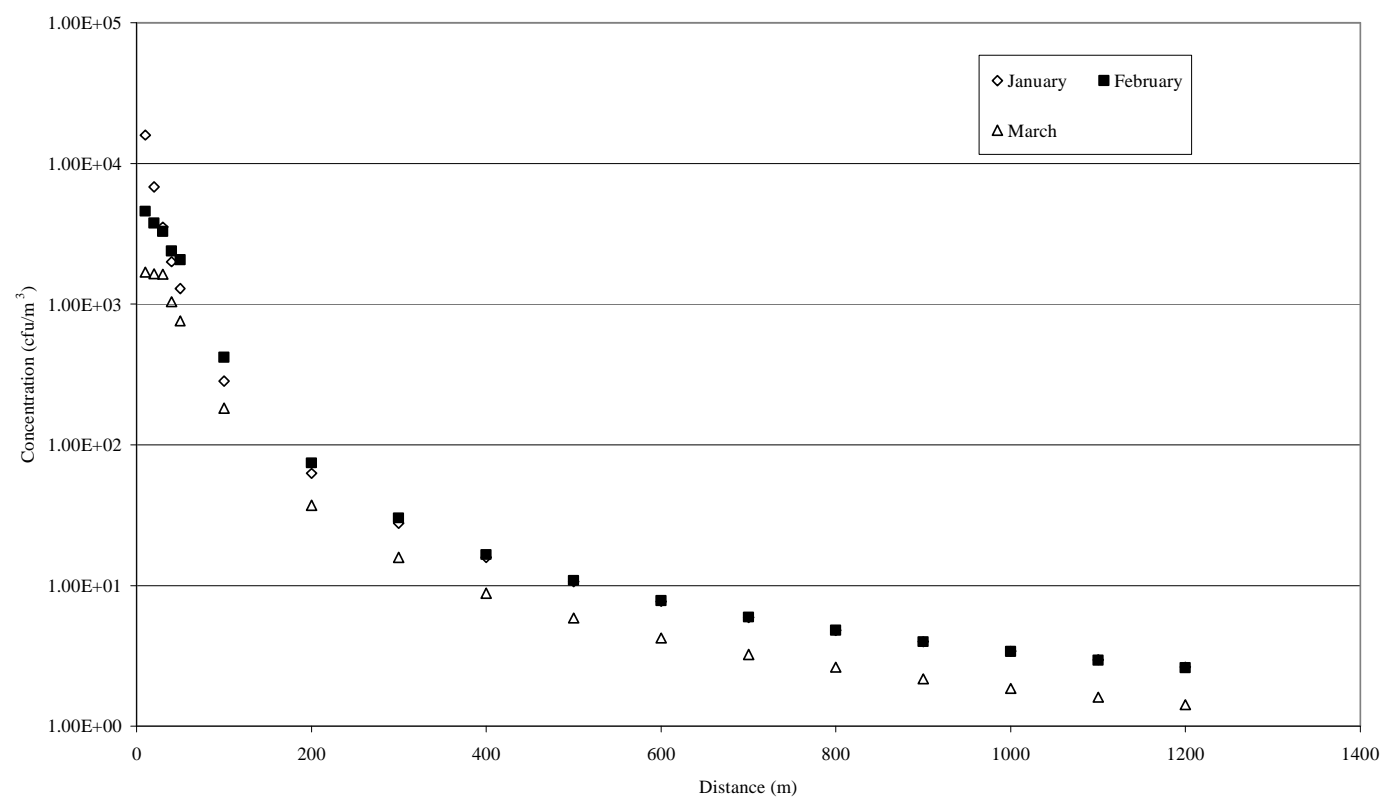

Fig 11. Estimated depletion curves of actinomycetes using the ADMS model for combined active and passive sources on three separate dates. 